\title{
ISABEL DE VEGA, POETA CON MUSA \\ (ALCALÁ, 1558, 1568)
}

Nieves Baranda Leturio

UNED

nbaranda@flog.uned.es

\section{RESUMEN}

Isabel de Vega vivió en Alcalá de Henares hacia mediados del siglo XVI. Se desconoce su entorno social, aunque mantuvo contactos con otros escritores y nos legó catorce poemas. Este artículo examina su posible identidad social, reúne toda la información sobre sus textos y estudia sus poemas y lo que implican para una escritora de su época. Se añaden como apéndice sus poemas aún inéditos.

PALABRAS ClAVE: Escritoras, siglo XVI, poesía cancioneril.

\section{Abstract}

Isabel de Vega lived in Alcalá de Henares, near Madrid, in mid-sixteenth century. Her social background is unknown although she was in touch with other writers and she left up to fourteen poems. This article explores her possible social identity, gathers all the information on her texts and studies her poems and their meaning for a woman writer of the time. An edition of the poems in the Paris manuscript is included as an appendix.

KEYWORDS: Spanish women writers, sixteenth century, cancionero poetry.

Miguel Ángel Pérez Priego sorprendía a la crítica en 1989 con la publicación de un libro titulado Poesía femenina en los cancioneros. No era el estudio inaugural del tema, pero sí el primero en darle visibilidad y relevancia más allá de los foros de especialistas, en 
recabar toda la información disponible y en poner sobre la mesa los textos, que hasta entonces había que perseguir por cancioneros varios. El profundo conocimiento que el editor tenía de la poesía de la época y su rigor profesional largamente demostrado certificaban que la escasa muestra presentada era todo lo que podía reunirse ${ }^{1}$, de modo que no es raro que se convirtiera en referencia ineludible y que aún lo siga siendo. Un desconocedor del tema quizá pensara que es lógico que sean pocas autoras por tratarse de la Edad Media, pero que con la llegada del humanismo que impulsó con fuerza la educación habría un cambio, no obstante se trataría de un error. Más bien a la inversa, porque a pesar de la intensidad que adquiere la cultura escrita en el avance del siglo XVI, las mujeres creadoras siguieron siendo un exotismo apenas visible hasta casi finales del siglo. Como rara avis destaca Isabel de Vega, que se puede considerar la heredera de esas poetas del Cancionero general ${ }^{2}$.

Isabel de Vega nos ha legado una docena larga de poemas, entre los cuales hay uno dedicado al príncipe don Carlos que se presenta con esta rúbrica: «Soneto de la misma al príncipe don Carlos de España, sobre este verso de David: Omnia ecelsa tua et fluctus tui super me transierunt» ${ }^{3}$. El lector avisado reconoce que el salmo es uno de los que se emplea en el oficio de difuntos y deduce que se puede tratar de una elegía; quien no lo sabe se sorprende al llegar al inicio del último terceto, donde dice «passó sin hacer daño». El contenido del soneto es una larga enumeración descriptiva construida sobre antítesis que subrayan las virtudes del difunto frente a las pocas oportunidades de que gozó y concluye con un pareado que sintetiza conceptualmente el desarrollo: «el príncipe don Carlos desdichado/ a quien Fortuna el rostro no ha mostrado». En 1568, año de la muerte del heredero al trono, no se había extendido aún esa moda de honras fúnebres públicas que asolará el siglo XVII. Por otro lado las circunstancias de la muerte del príncipe, su larga convalecencia y los problemas políticos con su padre hasta el encerramiento quizá retrajeron a algunos de los aduladores habituales, que prefirieron no ahondar en la cuestión, a pesar de los suntuosos funerales que se le hicieron ${ }^{4}$. Le dedicaron elegías Francisco de Figueroa, en tercetos; quizá fray Luis de León ${ }^{5}$ si se acepta la discutida atribución de una canción; y Sánchez de las Brozas que escribió un poema en latín ${ }^{6}$. Junto a estos poemas mencionados

\footnotetext{
${ }^{1}$ Pérez Priego, Miguel Ángel, ed. (1989), Poesía femenina en los cancioneros, Madrid, Castalia. El corpus de poemas fijado en ese libro ha continuado con mínimas adiciones, por ejemplo de Gómez-Bravo, Ana M. (2003), “"A huma senhora que lhe disse”: sobre la práctica social de la autoría y a noción de texto en el Cancioneiro geral de Resende y la lírica cancioneril ibérica», La Corónica, 32.1, pp. 43-64; véase asimismo la base de datos de BIESES, , (proyecto FFI2012-32764 del que forma parte esta investigación), donde se añade otro poema anónimo de respuesta a Álvarez Gato.

2 Para las escritoras del siglo XV y XVI y sus dificultades como voz pública vid. Baranda, Nieves (2006) Cortejo a lo prohibido. Lectoras y escritoras en la España moderna, Madrid, Arco Libros, pp. 123-149 en particular.

${ }^{3}$ Se trata de una cita parcial del salmo 41,8, que en su versión completa se inicia «Abyssus abyssum invocat, in voce cataractarum tuarum; omnia excelsa tua, et fluctus tui super me transierunt»; una traducción literal sería «el abismo llamó al abismo al ruido de tus compuertas; todas tus cumbres y oleajes han pasado sobre mí». Para la cita del poema sigo mi edición en Baranda, Nieves (2009) «Notas para un cancionerillo de poetas cortesanas del siglo XVI» Revista destiempos, 4, 19, pp. 8-27, en p. 23 http://www.destiempos.com/n19/ dossierescritoras.pdf [consultado 10/10/2014]. Para la fuente de los poemas de Vega vid. infra.

${ }^{4}$ Preparó la edición del volumen Juan López de Hoyos (1568), Relación de la muerte y honras fúnebres del serenísimo Príncipe Don Carlos, Madrid, Pierres Cosin.

5 Vid. Camacho Guizado, Eduardo (1969), La elegía funeral en la poesía española, Madrid, Gredos.

${ }^{6}$ Ramajo Caño, Antonio (1993) «Huellas clásicas en la poesía funeral española (en latín y romance) en los siglos de oro», Revista de filología española, 73, pp. 313-328.
} 
por la crítica en estudios de poesía funeral o elegíaca, el olvidado poema de Isabel de Vega destaca por su rareza. El Brocense eleva al príncipe a las estrellas, junto a Escorpión; la canción atribuida a fray Luis explica que la muerte no ha esperado más a llevárselo, porque estaba llamado a tal gloria que ella misma hubiera resultado vencida; y Figueroa lo hace cortesano celestial en el más allá y lo llama «gloria de la gloria». A diferencia de estos panegíricos hiperbólicos hasta la desmesura, tan propios de la tradición encomiástica a la monarquía, el soneto de Vega escoge resaltar los valores de una dimensión puramente humana, que contrasta con las circunstancias que le envía un hado adverso y hasta alude dos veces a su falta de poder: «con mano larga y de poder desnudo»; «alto estado, grandeza, abatimiento;/ prisión y libertad». Si la rúbrica no aclarara a quién iba dirigido, pensaríamos que se describía a alguien afectivamente próximo a la poeta ${ }^{7}$.

El aprecio que Isabel de Vega muestra por la dimensión humana del príncipe sugiere que lo conoció o que tuvo más noticias de las habituales en un trato distante de la corte o los rumores propios de un entorno más alejado. Con seguridad entre ellos hubo alguna forma de comunicación, directa o por intermediarios. En 1558 moría en Yuste el emperador Carlos. Entre las elegías existe un soneto de Isabel de Vega «a la muerte del emperador Carlos V nuestro señor», que en los dos manuscritos conservados va seguido de otro poema, en décimas, cuya rúbrica lee: «De la misma al prínçipe don Carlos, porque aviendo visto este sonecto dixo que no hera possible averle hecho muger» ${ }^{8}$. Estamos, pues, ante un diálogo implícito entre el príncipe y la poeta, que recibe noticias desde la corte y prepara una respuesta, solo comprensible si encuentra un cauce para llegar hasta su interlocutor. Los entornos reales son tan reducidos y controlados que debemos preguntarnos quién era esta desconocida Isabel de Vega para lograr que sus poemas llegaran a manos tan elevadas, llamar la atención de un joven Carlos adolescente y abrir con ello un diálogo, a pesar de la estrecha vigilancia de los círculos cortesanos siempre atentos al posible reparto de favores. Las circunstancias de esta relación nos son totalmente desconocidas e Isabel de Vega es un nombre común y por eso difícil de rastrear. Por poner ejemplos extremos se llamaba así una de las putas que menciona Rodrigo de Reinosa en las Coplas a la chinagala; pero también la hija de Juan de Vega, Marquesa de Bivona ${ }^{9}$. De la escritora es seguro lo que dice Juan Pérez de Moya en su Varia historia de santas e ilustres mujeres, ${ }^{10}$ que la cita como poeta y la sitúa en Alcalá de Henares, precisamente la localidad en la que el Príncipe Carlos (1545-1568) vivirá desde 1561 y hasta junio del año siguiente para asistir a la universidad y nuevamente en 1563 .

\footnotetext{
${ }^{7}$ Ed. cit., pp. 24-25. Para la biografía del príncipe vid. Moreno Espinosa, Gerardo (2006), Don Carlos el príncipe de la leyenda negra, Madrid, Marcial Pons.

${ }^{8}$ Así en el Ms. 617 de la Biblioteca Real de Madrid; en el cancionero de París la rúbrica lee un escueto «Coplas», ambos testimonios descritos infra.

9 Puerto Moro, Laura (2010), Obra conocida de Rodrigo de Reinosa, San Millán de la Cogolla, Cilengua, pp. 190-195, en p.193. En Baranda, Nieves (2009), p. 13, sugerí erróneamente que la hija del embajador Juan de Vega pudiera ser la poeta, pero vivió toda su edad adulta en Italia, y si no nació allí, ahora sé que murió en Sicilia el 3 de enero de 1558, vid. una biografía y algunas cartas en Rahner, Hugo (2007), Saint Ignatius Loyola. Letters to Women.

${ }_{10}$ Varia historia de sanctas e illustres mujeres, ed. de Baranda Leturio, Consolación (1998) Madrid, Fundación José Antonio de Castro, p. 989; la primera edición de la obra, relevante para establecer el ante quem de la cita, es de Madrid, 1583.
} 
En 1557 Cristóbal de Vega, eminente catedrático de la universidad de Alcalá de Henares, que tiene pacientes tan notables como la princesa de Éboli, el duque de Medinaceli o María de Mendoza, es nombrado médico de la casa de Felipe II. El rey está de viaje en los Países Bajos, así que no es para atenderle a él, sino a su hijo don Carlos, como el mismo de Vega pone en la portada del libro que termina ese año y publica en 1564: Caroli Hispaniarum Principis Max. medici a cubículo. ${ }^{11}$ La relación entre médico y paciente será estrecha quizá bastante íntima, dada la complicada salud del príncipe. Para trazar un hilo directo entre la poeta y el príncipe, habría sido oportuno que una de las hijas del médico se llamara Isabel, aunque es descartado por las actas de bautismo de los hijos que Juan Catalina García encontró en la parroquia de Santa María de Alcalá ${ }^{12}$. No obstante, el mismo autor cita una carta de Álvar Gómez de Castro, fechada en septiembre de 1561 y destinada a un «Doctori regio» no identificado, donde le habla de una enfermedad que había padecido y se despide saludando a su familia: «Marcum puerum ingeniosissimum, Isabellam modestissimam puellam...». Más que sugerir un vínculo posible con esta familia a través de esposas, sobrinas, etc., que el doctor y la poeta que viven en la misma ciudad y por la misma época compartan apellido nos recuerda que para escribir poesía como lo hace Isabel era necesario haber recibido una alta educación y que las mujeres de la época solo podían adquirirla en dos entornos: la corte o las familias de la elite intelectual universitaria.

La corte real de Isabel de Valois no era el único lugar de refinamiento y atracción literaria. En Alcalá de Henares, que ocupaba un punto clave en el triángulo dibujado por Madrid, Guadalajara y Toledo tenía un fuerte arraigo la familia Mendoza, cuyas mujeres estaban entre las más cultas del momento: María Pacheco y a su hermana la Condesa de Monteagudo, citadas por Lucio Marineo Sículo, María de Mendoza, discípula de Álvar Gómez de Castro, Luisa de la Cerda, la princesa de Éboli se acompañaban por otras damas, hombres eruditos, nobles e intelectuales ${ }^{13}$. A su estela y en el mismo entorno cortesano no desentonarían otras mujeres educadas y con interés por la poesía. El soneto de Isabel de Vega dedicado a un "gran Hurtado», que solo puede ser «de Mendoza», es testimonio de una relación literaria con ese entorno, no solo en el elogio, sino en lo explícito de la protección: «Pues si quiero mostrarme agradesçida/ al verso heroico con que favoreces/mi musa indigna de tan gran renombre,/ atájame entender lo que mereçes/

${ }^{11}$ Hernández, Justo (1997), Cristóbal de Vega (1510-1573) y su «Liber de Arte Medendi» (1564, Valencia, Universidad; e ídem (2001), «Cristóbal de Vega (1510-1573), médico de cámara del príncipe don Carlos (1545-1568)», DYNAMIS. Acta hispanica ad medicinae scientiarumque historiam illustrandam, 21, pp. 295232; agradezco al autor la paciente respuesta a mis consultas y la ayuda que me ha prestado en este aspecto.

${ }_{12}$ Biblioteca de escritores de la provincia de Guadalajara y bibliografía de la misma hasta el siglo XIX, Madrid, Sucesores de Rivadeneyra, 1899, p. 541. La esposa se llamaba María de Salas y sus hijos Catalina y Tomás; hay una hija anterior de otra esposa llamada Estebanica.

13 Aún necesitamos un estudio definitivo sobre el tema que reúna en perspectiva común muchos datos particulares que se han ido acumulando, vid. por ejemplo, García Sánchez, Justo (1993), Las Vestales romanas, tratado de Álvar Gómez de Castro, año 1562, Oviedo, Universidad de Oviedo, pp. 97- 111; Vaquero Serrano, Carmen (1996), En el entorno del maestro Álvar Gómez: Pedro del Campo, María de Mendoza y los Guevara, Ciudad Real, Oretania; Hidalgo Ogáyar, Juana (1999), «Residencias de los Mendoza en Alcalá de Henares», Indagación: revista de historia y arte, 4, pp. 177-184; ídem (2002), Los Mendoza y Alcalá de Henares: su patronazgo durante los siglos XVI y XVII, Alcalá de Henares, Universidad (en realidad estudia a las Mendoza); Nader, Helen ed. (2004), Power and Gender in Renaissance Spain. Eight Women of the Mendoza Family, 1450-1650, Urbana/ Chicago, University of Illinois Press; y Dadson, Trevor J. (2011), «The Education, Books and Reading Habits of Ana de Mendoza y de la Cerda, Princess of Éboli (1540-1592) », en Cruz, Anne J. y Hernandez, Rosilie, eds., Women's Literacy in Early Modern Spain and the New World, Burlington/ Farnham, Ashgate, pp.79-102. 
y ver que es ynposible la suvida/ a pretender loar tu claro nombre». Sin nombre de pila no resulta fácil decidir si se dirige a Juan Hurtado de Mendoza, III señor de Torote, o a Diego, el embajador, hijo del Conde de Tendilla, porque ambos fueron poetas coetáneos de Vega y mantuvieron relación con Alcalá. A favor de que se trate de D. Juan está su condición de mecenas literario, promotor de justas poéticas en Alcalá, destinatario de versos de muchos intelectuales del momento que tienen su punto de unión en torno a la universidad (Luis de la Cadena, Ambrosio de Morales, García Matamorios, Álvar Gómez de Castro) y defensor de mujeres poetas como Catalina Paz ${ }^{14}$. Para sustentar que se pueda tratar del gran poeta don Diego, aunque su presencia en Alcalá sea más esporádica, cabe señalar que en el mismo cancionero 373 de la Biblioteca Nacional de París, donde aparecen los de Vega, hay tres sonetos y unas coplas suyos, y que la fecha conocida de muerte en 1575 casa mejor con una Isabel cuya actividad se data entre 1558 y 1568, aunque pudiera extenderse mucho más considerando la ausencia de datos.

La vida de Isabel de Vega pudo trascurrir en la corte o quizá el mundo de los profesores o intelectuales de la universidad de Alcalá, que explicaría su relación con las letras, semejante a algunas mujeres humanistas cronológicamente algo anteriores y en su mayoría familiares de grandes intelectuales, formadas en un medio que tenía fe en el valor de la cultura y que compartía las ideas más avanzadas sobre las mujeres. De ser así la educación y sobre todo la dedicación de Isabel de Vega a la poesía procedería de un ambiente similar al que vio florecer a Francisca de Nebrija, Luisa y Ángela Sigea, Lucía de Medrano o Isabel de Vergara ${ }^{15}$. A diferencia de los hombres, las mujeres gozaban de muy escasa movilidad social, carecían de una carrera profesional u otras posibilidades de labrar un círculo propio, así que se apoyaban sobre todo en las relaciones de sus círculos familiares, naturales o matrimoniales. En este aspecto los humanistas de alto reconocimiento ocupaban un lugar privilegiado, porque desde su cuna, a veces muy humilde, podían llegar a alcanzar por sus relaciones un amplio espectro de estamentos, incluida la corte. Siendo plebeyo, Cristóbal de Vega, por ejemplo, abarcaba en sus círculos a sus colegas profesionales, a familias aristócratas y hasta la familia real. Isabel de Vega, culta, con dotes para la poesía, podría llegar lejos a través de las relaciones familiares, a la cámara del príncipe y a los círculos de poetas. Su relación con el primero explicaría ese extraño soneto a su muerte. Su relación con los segundos se plasma en el soneto a Hurtado de Mendoza, en la cita que hace de ella Pérez de Moya y en el poema que escribe a Diego Ramírez Pagán y que éste selecciona para la edición de sus poesías ${ }^{16}$. Esta presencia sugiere que Isabel de Vega gozó de cierta prédica (¿literaria, social?) en su entorno, porque Ramírez Pagán era un escritor muy atento a los mecenazgos, sumamente

${ }^{14}$ Se desconoce su fecha de muerte, que tiene que ser posterior a 1558, según el estudio de Alonso, Dámaso (1972), «Un poeta madrileñista, latinista y francesista» Obras completas. II. Estudios y ensayos sobre literaturaBoletín de la Real AcademiaBuen placer trovado

${ }^{15}$ Vid. Baranda, Nieves (2004), «Mujeres y cultura en la época de Isabel la Católica», Ínsula, 691-692, pp. 27-28; e ídem (2008), "Luisa Sigea, la brillante excepción femenina», Melchor Cano y Luisa Sigea. Dos figuras del Renacimiento español, ed. de Miguel Ángel Pérez Priego, Cuenca, Ayuntamiento de Tarancón/ Centro Asociado de la UNED de Cuenca, pp. 129-151.

${ }^{16}$ Ramírez Pagán, Diego (1562), Floresta de varia poesía, Valencia, Juan Navarro, con edición moderna de Barcelona, Selecciones Bibliófilas, t. II, p. 60; sobre este poeta y su relación con mujeres escritoras vid. Baranda, Nieves (1998), «La Marfira de Ramírez Pagán, ¿otra mujer poeta del siglo XVI?», en Actas del XIII Congreso de la Asociación Internacional de Hispanistas, Madrid, Castalia, etc., t. I, pp. 272-281. 
cuidadoso con la imagen y las relaciones, que no iba a introducir a la poeta en su obra si no lo consideraba favorable para su propia representación. La relación entre ambos posiblemente provenía de la época en que el murciano estudió en Alcalá, donde fue laureado en unas justas poéticas y se codeó con nobles, intelectuales y otros literatos, círculos similares a los que reflejan estos poemas de Isabel de Vega, aunque ella no tuviera acceso a las aulas de la universidad ${ }^{17}$.

El corpus de Isabel de Vega se compone de catorce poemas que han sido transmitidos en las siguientes compilaciones:

- El Cancionero de poesías varias contiene seis composiciones seguidas ${ }^{18}$ atribuidas por la rúbrica: «Cancioncilla de doña Ysabel de Vega, con glossa», $1^{\circ} \mathrm{v}$ : «De una herida mortal» [glosa a Tanto puede la afliçion]; "Glossa de la misma a este villançico», $1^{\circ}$ v. «Si pudiesse con la vida» [glosa a Nunca más verán mis ojos]; «Coplas de la misma», $1^{\circ} \mathrm{v}$ : «Ni basta disimular»; «Sonecto de la misma señora a la muerte del Emperador Carlos Q.R.D.S.P.», $1^{\circ} \mathrm{v}$. « $i \mathrm{O}$ muerte, quanta gloria as alcançado»; «De la misma al prinçipe don Carlos, porque aviendo visto este sonecto dixo que no hera possible averle hecho muger», $1^{\circ} \mathrm{v}$ : «Muy alto y muy poderoso»; «Sonecto de la misma al prinçipe don Carlos de España sobre este verso de David: o[mn]ia eçelssa tua et flutus tui super me transierunt», $1^{\circ} \mathrm{v}$ : «Divino ingenio, lengua cassi muda».

- El Recueil de poésies castillanes du XVIe et du XVIIe siècle de la Biblioteca Nacional de París ${ }^{19}$ tiene diez poemas separados en tres partes distintas, con atribuciones dadas principalmente en iniciales: f. 68r-v, «Soneto de d. y. de Vega a la muerte del emperador Carlos V nro. Sr.», $1^{\circ}$ v: «O muerte quanta gloria[s] as alcançado»; ff. 68v-69v «Coplas», $1^{\circ} \mathrm{v}$ : «Muy alto y muy poderoso»; f. $221 \mathrm{v}$. «Soneto De D. Y. d. V. a esta copla», $1^{\circ}$ v.: «Si muero por seruirte estando ausente»; f. 222v «Soneto De y. d. V.», $1^{\circ}$ v: «Deçidme los leales amadores»; f. 223 «Soneto De la mesma», $1^{\circ} \mathrm{v}$ : «Mi sentimiento esta tan ocupado»; f. $223 \mathrm{v}$ «Otro De la mesma», $1^{\circ}$ v: «Dizen que es muy cruel yniqua y dura»; ff. 224-225 «letra,/ Tanto puede la afiçion/ quando con fe perseuera/ que do premio no se espera/ de alli saca galardón/ glosa D. y. D. V.», v $1^{\circ}$ v: «De vna herida mortal»; ff. 274v-275 «Esparsa d. d. y. d. V.», $1^{\circ}$ v: «Gran disfauor me da amor»; f. 275 «Otra Del M${ }^{\circ}$ s», $1^{\circ} \mathrm{v}$ : «Despues que amor me hizo guerra»; f. $275 \mathrm{v}$ «Soneto D. y. D V.», $1^{\circ} \mathrm{v}:$ « Si llegara mi pluma o gran Hurtado».

17 Vid. Ramírez Pagán, Diego (1998), Sonetos, ed. de López García, David y Siminiani Ruiz, Rosario, Murcia, Real Academia Alfonso X el Sabio, pp. 11-21, para la biografía del poeta.

${ }_{18}$ Cancionero de poesías varias, Ms. 617 de la Biblioteca Real de Madrid, ed. de J. J. Labrador, C. A. Zorita y R. A. Di Franco, Madrid, El Crotalón, 1986, n 487-492, pp. 551-554; los editores afirman que la letra de copia es del último tercio del siglo XVI y que el contenido tiene dos partes: la primera con poesías del cuatrocientos y la segunda, donde están los poemas de Vega, del quinientos. Los textos fueron incluidos por Baranda, Nieves (2009), «Notas para un cancionerillo...», art. cit.

${ }_{19}$ Manuscrito Espagnol 373 ( olim Saint-Germain-Gèvres, $\mathrm{n}^{\circ}$ 137), copia en limpio, letra unitaria, 328 hs., 205 x 142 mm, según el catálogo de la biblioteca, que ofrece una relación detallada del contenido, al igual que Morel-Fatio, Alfred (1892), Catalogue des manuscrits espagnols et des manuscrits portugais, Paris: Imprimerie Nationale, $n^{\circ}$ 602. Las iniciales que emplea el copista para identificar a Isabel de Vega no se pueden confundir con las de otros poetas del cancionero. 
- Cancionero, Ms. 3095, de la Biblioteca Riccardiana de Florencia. Aquí los dos poemas de Isabel de Vega aparecen anónimos: f. 56v «[Redondilla] Tanto puede la afición/ quando con fe perseuera/... de allí saca galardón»; ff. 56v-57v «Glossa [a la anterior]/ [Décimas, 4] De una herida mortal/ que solo Amor pudo dalla/... de allí saca galardón»; f. 59 «Soneto./ Deçidme los leales amadores/ si allais en amor contentamiento/... pues sea el neçio solo amante fino» ${ }^{20}$.

- Diego Ramírez Pagán, Floresta de varia poesía: «Respuesta de doña Ysabel de Vega», $1^{\circ} \mathrm{v}$ : «Dardanio, que tan dulce has celebrado» ${ }^{21}$.

Los catorce poemas de Isabel de Vega pueden parecer un corpus mínimo en relación a otros escritores, pero si lo comparamos con los de autoría femenina en el período, se trata de un número muy elevado de composiciones, que confirma la importancia que tuvo en su entorno y la buena circulación sus versos, puesto que resulta excepcional su inclusión en tres cancioneros distintos ${ }^{22}$. Si como indicio el número tiene un alto valor, resulta una selección menguada para hacer cualquier afirmación rotunda, en particular porque debemos contar con que existió un corpus mucho mayor perdido, así cualquier valoración sobre su poesía debe tener un carácter meramente tentativo aceptando que se fundamenta en lo que la transmisión, es decir, la casualidad ha querido legarnos. Partiendo de esta premisa, se observan los siguientes rasgos: dedicación por igual a los géneros de la tradición cancioneril y petrarquista, predominio del tema amoroso, que se complementa con los circunstanciales, preferencia por desarrollos breves de carácter conceptual.

Isabel de Vega debe situarse por la cronología conocida y las características de sus versos entre los poetas que la crítica denomina del medio siglo, que beben igual de la poesía castellana y de la italiana a través de fuentes impresas. Para la primera contaban con la larga tradición y modelos del Cancionero general, para la segunda con las obras de Boscán y Garcilaso impresas desde 1543, y ahí están los fundamentos de la poesía de Vega, aunque en ambas se detecten las renovaciones que se introducen por otras vías ${ }^{23}$. En este aspecto el corpus presenta una muestra casi igual de ambas corrientes: dos glosas, dos coplas, dos esparsas y ocho sonetos. Entre estas formas la más llamativa es la esparsa, por tener sabor de género arcaizante. Son coplas sueltas, una de ocho versos y la otra de diez, ambas con cuatro rimas, si bien distribuidas de forma distinta, cruzadas en «Gran disfavor me da amor», que consta de diez versos; y abrazadas en «Después

${ }^{20}$ Sigo las descripciones de Cacho, María Teresa (2001), Manuscritos hispánicos en las bibliotecas de Florencia. Vol. II, Florencia, Alinea Editrice, p. 326.

${ }^{21}$ Edición citada; el mismo poeta le dedica un soneto de elogio (t. II, p. 59) y Álvaro Alonso sospecha, con buen criterio, que podrían estar dirigidos a ella algunos poemas más destinados a una Belisa, vid. «Isabel de Vega», en Romero, Dolores (2007) et al., Seis siglos de poesía española escrita por mujeres. Pautas poéticas y revisiones críticas, Berna, Peter Lang, pp. 75-84.

${ }^{22}$ Lo más habitual en las mujeres poetas anteriores o posteriores es que sean testimonios únicos, con frecuencia hológrafos, así con Leonor de la Cueva y Silva o Marcia Belisarda; solo Catalina Clara Ramírez de Guzmán escapa a esta maldición. Para todas ellas pueden verse ediciones y fuentes en la base de datos BIESES, http://www.bieses.net. Esta importancia en su medio corrobora la hipótesis sobre las causas por las que Ramírez Pagán la incluía en la Floresta y le dedicaba ese soneto laudatorio, de los que se reservaban a mecenas o colegas bien conocidos cuya relación adornaba al propio autor.

${ }_{23}$ Vid. Alonso, Álvaro (2002), La poesía italianista, Madrid, Ediciones del Laberinto, pp. 143-160; y López Bueno, Begoña, coord. (2011), La renovación poética del Renacimiento al Barroco, Madrid, 2011, pp. 60-68, manuales que señalan con nitidez los rasgos de estos poetas. 
que amor me hizo guerra», formada por ocho versos. Se trata de un género que adquiere importancia desde mediados del siglo XV con el gusto por el conceptismo, que desarrolla en una estrofa única de forma muy condensada un pensamiento que parte de una circunstancia amorosa. En tanto que fórmula poética no desaparecerá, ya que el madrigal o el epigrama se ajustan a la misma función, sin embargo, la esparsa como tal, que sí está presente en el Cancionero general, no interesa aparentemente a poetas coetáneos de Vega, y no encontramos esa denominación en ninguna rúbrica de Diego Hurtado de Mendoza Montemayor, Ramírez Pagán ni tampoco en otros poemas del mismo cancionero de París donde están las nuestras ${ }^{24}$. La estructura de ambas composiciones es distinta: «Después que amor me hizo guerra» parte de ese motivo circunstancial para expresar a través de paradojas de conceptos antitéticos la situación del enamorado; «Gran disfavor me da amor» tiene una organización similar a la de la glosa, ya que concluye con una sentencia o mote: «mas al fin podré dezir:/ a mi mal ningún remedio», cerrando así entre el primer verso y el último de la esparsa su sentido. Esta estructura conclusiva, que también tienen las glosas parece ser una de las preferidas de Vega, que la aplica con virtuosismo técnico. Adopta en las glosas la forma más canónica: cada verso de la cancioncilla que consta de tres o cuatro se sitúa al final de una copla real, que exprime su sentido y lo desarrolla, además en la que comienza «De una herida mortal» se vuelve a repetir en anadiplosis con ligera variante o sin ella al comienzo de la estrofa siguiente ${ }^{25}$. En los ejemplos disponibles la coplilla parece ser de la misma poeta y se aleja de lo popularizante de otros autores del período que optan por formas más musicales o ligeras, ya que respeta las convenciones de la expresión amorosa cortés. En su artificiosidad y gusto por la exhibición de la propia destreza como un juego conceptual le cabe bien a esta poesía el uso cortesano o social que testimonian otros poemas de Vega.

Se ha señalado cómo mucha de la poesía femenina conservada para este período forma parte de intercambios dialógicos, lo que parece consecuencia de que ha sido copiada precisamente porque servía para dar pleno sentido a los versos masculinos, así lo testimonian parte de los poemillas, coplas, motes, sentencias recogidos en la antología de Miguel Ángel Pérez Priego. No cabe decir que sucede lo mismo con Isabel de Vega, aunque cinco de los catorce poemas responderían a esta condición, porque se dedican a algún hombre: Ramírez Pagán, el príncipe Carlos, el emperador o Hurtado de Mendoza; los restantes, de tradición castellana o italiana, son todos de tema amoroso. Para la Vega cancioneril amor equivale a sufrimiento y el amante debe buscarlo incluso: las dos glosas abundan en esa idea con un extenso desarrollo, al igual que las coplas «Ni bastan disimular»: «pues mucho más persevero/ mientras más el mal porfía» ${ }^{26}$. Aunque los sonetos expresan el servicio de amor y eso implica súplica y sufrimiento, el discurso sale

${ }^{24}$ Para la esparsa en el siglo XVI vid. Pérez Bosch, Estela (2009), Los valencianos en el cancionero general. Estudio de sus poesías, Valencia, Universitat de València, pp. 272-275.

${ }^{25}$ Baehr, Rudolf (1970), Manual de versificación española, Madrid, Gredos, pp. 330-339; el ejemplo de Lope que incluye (pp. 333-334) sigue un patrón parecido de repetición entre verso último y primero de algunos términos. Vid. Esteva de Llobet, M $^{\mathrm{a}}$ Dolores (2012), «La glosa poética en la poesía de Jorge de Montemayor», en Estudios sobre el «Cancionero general»(Valencia, 1511). Poesía, manuscrito e imprenta, Valencia, Universitar de València, pp. 461-477, que para su análisis traza un panorama de la evolución de este género.

${ }^{26}$ Puede verse a modo de muestra del vocabulario amoroso de Vega el gráfico generado en wordle al final del artículo. 
del ensimismamiento al dirigirse a un tú, ya sea una «señora», los «leales amadores» o un interlocutor no explicitado. Con ellos puede establecer argumentaciones que evitan la introspección conceptual para plantear salidas, entre las cuales incluso cierta felicidad o alivio es posible, así el soneto «Dizen que es muy cruel» pide que su merecimiento sea pagado; «Mi sentimiento está tan ocupado», expresa su felicidad por contemplar la imagen de la amada impresa en su alma, que es un alivio; y «Deçidme los leales amadores» descalifica al amador: "pues sea el necio amante fino/ y un noble pecho no sufra desdenes», con lo que se invierte la escala de valores anterior. En su planteamiento destaca la apelación a la razón para dominar al amor: «y venza la razón en ti, señora,/ al desamor que reina injustamente, » dice en «Si muero por servirte»; y ambos están de acuerdo («Razón y amor en esto están a una») en el que empieza «Dizen que es muy cruel». Se trata de conceptos muy presentes en la poesía de Ausias March, de quien parece haber tomado otras influencias, por ejemplo, el traslado del apóstrofe a los «leales amadores», que estaba ya presente en un octosílabo de Mena y entre los poemas de March que tradujo Jorge de Montemayor ${ }^{27}$. A esas poesías remite la contraposición sabio /necio que aparece en ese mismo soneto de Vega: «amor me agravia siempre en no pagarme:/ al nescio jamás falta, y lisongero,/ y nunca a mí determinó curarme», dice March ${ }^{28}$. Vega no sería una poeta de su tiempo si no pudiéramos detectar alguna influencia de Garcilaso o Boscán, aunque sea casi mostrenca como la que aparece en el soneto «Mi sentimiento está tan ocupado» a través del bien que mora en el alma y con el que se recrea la voz poética, sin embargo el desarrollo ulterior parece remitir a un léxico religioso con términos como «desabrimiento», «paciencia» «favores» o «clemencia».

El aspecto más llamativo de la poesía amorosa de Vega es la ausencia de una voz poética femenina, como correspondería a la autora. En este aspecto sucede lo mismo en las dos tradiciones poéticas que maneja: cuando se identifica el género del sujeto hablante, es masculino: «ni soy muerto ni soy vivo», «me contente con ser de vos amado», "cuando vivo me tienes», etc.; en correspondencia con un tú femenino al que se dirige: «señora», «mi enemiga». En algunos casos el discurso tiene un carácter neutro, porque el sujeto carece de marcas de género como en «Deçidme los leales amadores», "Gran disfavor me da amor» $\mathrm{y}$ «Ni basta disimular». Este problema ha sido cuidadosamente tratado por Elizabeth Boyce y Julián Olivares que lo explican por el decoro que impedía que las mujeres expresaran deseo hacia el hombre y por la existencia de un código poético fuertemente sexuado, donde la casuística amorosa solo contemplaba la posibilidad de un hablante masculino, así el receptor de la época solo vería cuestionada o desautomatizada su lectura homocéntrica a través de la rúbrica que reconocía una autoría femenina ${ }^{29}$. Por esta razón en el caso de Vega los poemas áulicos no son los más convencionales, como es habitual, sino los que expresan su identidad, porque en ellos sí se identifica como una

27 «Oyd, oýd leales amadores», Montemayor, Jorge de (1996), Poesía completa, ed. de Emilio Blanco, Madrid, Biblioteca Castro, p. 1110. También Acuña presenta ambos impulsos como contrapuestos, por ejemplo, en el soneto XIX pelean amor y razón, igual que en el LIII, «Con la razón en su verdad envuelta/ combate de atrevido mi querer», vid. Acuña, Hernando de (1982), Varias poesías, ed. de Luis F. Díaz Larios, Madrid, Cátedra, p. 226 y p. 274, respectivamente.

28 Ibídem, canto XLII, p. 1133.

${ }^{29}$ Olivares, Julián y Boyce, Elizabeth (2012), Tras el espejo la musa escribe. Lírica femenina de los siglos de oro, Madrid, Siglo XXI, pp. 24-37, edición revisada y aumentada respecto a la primera. 
hablante mujer: está «agradecida» a Hurtado de Mendoza, no quiere ser «sola» la que no cante a la muerte del emperador, como le dice a su nieto, y es Belisa quien se dirige a Ramírez Pagán. En los dos primeros adopta la posición de inferioridad adecuada, aunque con distintos matices. Para dirigirse al príncipe es por un lado una súbdita que llora la muerte del soberano y busca un guía en su desvalimiento, por otro una escritora que se califica con los topos de la humilitas, como la mea mediocritas («mi rudeza», «los que poco valemos») o el sermo rusticior («ninguno hablara/ de tanta materia sobra/ que más no la levantara»), por más que el propio texto por su mera formulación de poesía culta cuestione estas afirmaciones. En el que dirige a Hurtado de Mendoza existe una clara conciencia autorial al ofrecerse a usar su arte para consolar al poeta, en una identificación implícita con Orfeo: «mi musa con estilo no hurtado/ pusiera a tu tristeza gran consuelo». Las expresiones «mi pluma» $\mathrm{y}$ «mi musa», por más que esta pueda calificarse de «indigna» de un modo convencional, solo son posibles en un autor que se considera parte de la sociedad literaria y que entiende sus creaciones dentro de esta esfera intelectual selecta, de donde ha obtenido a su vez el reconocimiento necesario para dirigirse así a otro poeta.

La escasa producción de Isabel de Vega representa un paso cualitativo en la condición autorial de las mujeres escritoras. No se limita a ser una dama para quien la poesía no es más que otra forma de relación elegante en la sociedad cortesana, muestra de unas habilidades destinadas al juego o el galanteo, sino que es una escritora con plena conciencia de serlo. Para que este salto se haya producido no basta con que sea autora de un corpus extenso ni que su actividad de escritora se prolongue en el tiempo, sino que exige a la par el reconocimiento de la sociedad literaria de su época, que por encima de los posible prejuicios acepta que aunque su voz tenga que disfrazarse como masculina en algunas ocasiones, el poeta también puede ser mujer y por tanto tener musa.

\section{APÉNDICE $^{30}$}

[f. 221v.] Soneto de D. Y.d. v. a esta copla

Si muero por servirte estando ausente ablanda tu dureza matadora y aquella pertinaçia que en ti mora cuando vivo me tienes y presente.

Dexa torcer el braço tan valiente con que me derrocaste en sola un ora y venza la razón en ti, señora, al desamor que reina ynjustamente.

Después de muerto yo y tú arrepentida si a la razón quisieres sujetarte ternás dolor por ser desconocida.

Mas yo, que viviré siempre en amarte, quando el pesar te tenga y entristezida huyr desearé por consolarte.

${ }^{30}$ Se editan aquí los poemas inéditos incluidos en el manuscrito de París, Espagnol 373, de modo que junto con los ya publicados en Baranda, Nieves (2009), pp. 20-25, se pueda acceder al corpus completo de la poeta. Se respeta la ortografía original con excepción de las $u / v$ y se actualiza el uso de mayúsculas y la puntuación. 
[f. 222v.] Soneto de Y. D. V.

Deçidme los leales amadores

que buscáis en amor contentamiento

si por ventura os toman por descuento

los males que sufrís y los dolores.

Que está corto conmigo en dar favores

quanto largo en matar y dar tormento

líbrame una esperança allá en el viento

y a trueco de un placer da mil temores.

Mal aya quien le vusca y quien le sigue,

mal aya quien se çeva de sus vienes

pues salen a los ojos de contino.

Al más firme amador más le persigue:

pues sea el necio amante fino

$\mathrm{y}$ un noble pecho no sufra desdenes.

\section{[f. 223r.] Soneto de la mesma}

Mi sentimiento está tan ocupado

en contemplar el bien que en mi alma mora

que no escucha ni entiende, mi señora, de los agenos males el traslado.

$\mathrm{Y}$ tan contento en tan felize estado está mi corazón con lo que adora que no puede creer que sola un ora a nadie tenga amor tan enojado

Que amor al gusto da desabrimiento no más de por provar nuestra paçiençia y quien mejor merezca sus favores.

Después conforme a nuestro sufrimiento usando con nosotros de clemençia alívianos la pena y los dolores.

\section{[f. 223v.] Otro de la mesma}

Dizen que es muy cruel yniqüa y dura

la ley, que en general no comprehende, mas no lo haze amor, que si se enciende es más que pestilencia su locura.

Pues ved mi triste suerte y mi ventura que siendo de los que este crudo offende no alcança a mí la ley que los defiende amando más que amó jamás criatura.

Razón y amor en esto están a una y dizen que según lo que merezco me contente con ser de vos amado.

Mas que notando bien lo que padesco en todo el mundo ay cosa sino una que es vuestro amor con que este sea pagado. 
[f. 275r] Esparsa d. d. y.d. V.

Gran disfavor me da amor

[f. 275r] grande soledad padezco

pues se aumenta mi dolor

y según lo que merezco

pienso pasó lo menor,

pero tomaría por medio

no darlo tanto a sentir

a quien no ha de poner medio

mas al fin podré dezir:

«A mi mal ningún remedio».

Otra del $M^{\circ} s$

Después que amor me hizo guerra

hasta hazerme su captivo

ni soy muerto ni soy vivo

ni soy aire ni soy tierra.

Soy un fuego de Vulcano

que con agua más se aviva

si la cruda mi enemiga

no le apaga con su mano.

[f. 275r] Soneto D. y. DV.

Si llegara mi pluma, o gran Hurtado, qual la gloriosa tuya al terçer çielo de do truxiste con veloçe buelo de Apolo musas y el saver hurtado,

Mi musa con estilo no hurtado pusiera a tu tristeza gran consuelo, mas, ¡ay!, que en mí no ay más de desconsuelo y si viviere algún bien, será hurtado.

Pues si quiero mostrarme agradesçida

al verso heroyco con que favoreçes mi musa yndigna de tan gran renombre, atájame entender lo que mereçes

y ver que es ymposible la su vida

a pretender loar tu claro nombre. 


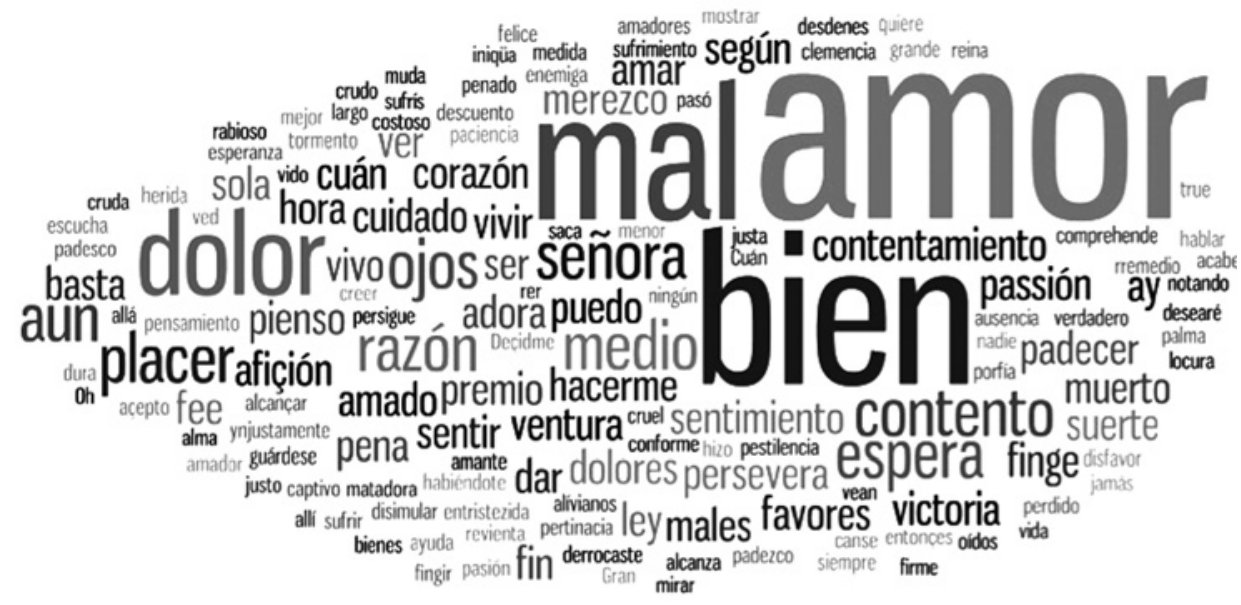

Representación de uso de palabras en los poemas amorosos de Isabel de Vega. Se han eliminado algunos términos sin peso semántico. 
